\title{
Translation Competences for Indonesian Novice Translators
}

\author{
Haru Deliana Dewi \\ harudd.dewi7@gmail.com \\ Faculty of Humanities, Universitas Indonesia
}

\begin{abstract}
Translation competence is a concept that everyone who would like to become a translator should know and understand. Moreover, novice translators or translation students need to achieve all translation competences if they desire to become professional translators. Thus, they must be taught about these translation competences. This paper is the result of a conceptual study, not an empirical one. It explores the literature on translation competences from Translation Studies scholars and adapts them for Indonesian novice translators to learn and achieve. This paper provides explanation, examples, and recommendations for translation students to accomplish translation competences. From the study, 13 translation competences are acquired and those are considered the most suitable with the recent situation of the translation industry in Indonesia. The number of these competences is a not a fixed one as it may decrease or increase in the future following the trends in the translation world.
\end{abstract}

Keywords: translation competences, professional translators, novice translators, translation students

\section{Introduction}

What is translation competence? Despite having been researched and developed frequently in many developed countries, the notion of translation competence has not been widely spread and acknowledged in Indonesia. Many in this country just consider translation as something to do with words, with language. Thus, someone who is a bilingual will be deemed capable of doing translation, but is this true? Is it sufficient for a bilingual to become a professional translator? Harris (1977) and Harris \& Sherwood (1978) proposed that natural translation is as one of the bilingual abilities, but Toury (1986) believes that bilingualism is just the foundation of translation competence, which means that being a bilingual is just a start of becoming a translator, but it will not suffice. There should be more than being a bilingual to be a translator.
Moreover, Lörscher (1986) asserts that professional translation is a developed form of natural translation. He believes that professional translation evolves from natural translation. Thus, this leads to an assumption that there are more than language or linguistic competences required for a novice translator to become a professional one. This study attempts to review most of the translation competences put forward by Translation Studies (TS) scholars and adjust them with the needs for the Indonesian novice translators to become professionals in the future.

\section{Translation Competence}

Before the discussion of what translation competences are, the paper will discuss why the word 'competence' is chosen and not the word 'competency', and discuss the definition of translation competence. According to Mulder et al. (2009), a competency is "an element of competence which is embedded in 
a certain situation", while competence is "a series of integrated capabilities consisting of clusters of knowledge, skills, and attitudes necessarily conditional for task performance and problem solving and for being able to function effectively in a certain profession, organization, job, role, and situation" (p.757). Hence, competence is a broader term than competency. Some TS scholars (Roberts, 1984; Delisle, 1992; Vienne, 1998) use the term 'translational competence' as the broader term to refer to 'translation competence', while 'translation competence' is part of this translational competence, while many more recent TS scholars (Shreve, 1997; Fox, 2000; Beeby, 2000; Schäffner, 2000; Kelly, 2007; Hurtado Albir, 2015; Cheng, 2017) prefer to use the term 'translation competence' as the umbrella term. Thus, the present paper will apply the term 'translation competence' following the more recent trend.

As for the definition, Shreve explains that translation competence is "a specialized form of communication competence", which is "about knowing about translation and about knowing how to do translation" (1997, p.120). He further asserts that the translation competences help translators produce wellformed translations which are "referentially accurate with respect to source texts, and socially appropriated in their cultural contexts" (1997, p.120). Moreover, PACTE (Process in the Acquisition of Translation Competence and Evaluation) defines translation competence as "the underlying system of knowledge and skills needed to be able to translate" (PACTE, 2000, p.100; PACTE, 2003, p.58; PACTE, 2011, p.33). Cheng in his dissertation (2017) defines translation competence as "a demonstrated ability to translate resulting from orchestrating a combination of knowledge, skills, and attributes in carrying out a given translation task under given conditions" (p.43). The present paper agrees with the definition from Cheng (2017), not only because it is the most recent one but also because it covers more aspects of what translation competence should consist of, such as knowledge, skills, and attributes.

\section{Sub-competences of Translation Competence}

This section will describe the subcompetences of translation competence that have been proposed by a number of TS scholars. First of all, Wilss suggested three subcompetences: (1) receptive competence in the source language (the ability to decode and understand the source text), (2) productive competence in the target language (the ability to use the linguistic and textual resources of the target language), and (3) super competence, the ability to transfer messages between the linguistic and textual systems of the source culture and the linguistic and textual systems of the target culture (1976, p.120). Roberts (1984) (adapted from Delisle, 1992) proposed five sub-competences of translational competence, namely: (1) linguistic competence, (2) translation competence, (3) methodological competence, (4) disciplinary competence, and (5) technical competence. Moreover, Vienne (1998) put forward only two basic elements of translational competence: (1) the ability to analyze a variety of translational situations and (2) the ability to decide on a strategy for resource research adjusted to the translational situation and the ability to evaluate and exploit the resources necessary to carry out the assignment received (pp.112-113).

Fox (2000) specified five translation subcompetences, such as communicative competence, socio-cultural competence, language and cultural awareness, learning how to learn, and problem solving goals. Beeby (2000) offered four sub-competences of translation competence for Spanish to English translation, and they are (1) transfer competence, (2) contrastive linguistic competence, (3) contrastive discourse competence, and (4) extra-linguistic competence. Schäffner (2000) proposed six translation sub-competences: (1) linguistic competence, (2) cultural competence, (3) textual competence, (4) domain/subject specific competence, (5) research competence, and (6) transfer competence. PACTE (2005) came up with six sub-competences from their research findings, and those are: (1) bilingual competence, (2) extra-linguistic competence, (3) knowledge about translation competence, 
(4) instrumental competence, (5) strategic competence, and (6) psycho-physiological competence. Kelly (2007) proposed seven subcompetences: (1) communicative and textual competence, (2) cultural and intercultural competence, (3) subject area competence, (4) professional and instrumental competence, (5) attitudinal or psycho-physiological competence, (6) interpersonal or social competence, and (7) organizational or strategic competence.

Hurtado Albir $(2007 ; 2015)$ proposed six sub-competences for translator training, namely (1) methodological and strategic competence, (2) contrastive competence, (3) extralinguistic competence, (4) occupational competence, (5) instrumental competence, and (6) translation problem-solving competence. Eser (2015) puts forward eight sub-competences, such as (1) bilingual competence, (2) cultural competence, (3) domain/thematic competence, (4) textual competence, (5) research and technological competence, (6) strategic competence, (7) knowledge about translation competence, and (8) translation service provision competence. NAATI (National Accreditation Authority for Translators and Interpreters) (2015) presents eight sub-competences for translators. Those are (1) language competence (in two languages), (2) intercultural competence, (3) research competence, (4) technological competence, (5) thematic competence, (6) transfer competence, (7) service provision competence, and (8) ethical competence (2015, p.7).

Thus, based on the sub-competences proposed by many TS scholars, we can see that several competences are similar, and a few are different. Those competences are perhaps adjusted with the language pair being discussed in each paper focusing on translation competences. Furthermore, they could be adapted with the time and the situation of the translation industry in each country of the TS scholars writing the papers on translation competences. Likewise, this paper will put forward translation competences that are suitable for Indonesian novice translators and with the translation industry in Indonesia.

\section{Translation Competences for Indonesian Novice Translators}

Based on the proposed sub-competences by many TS scholars above, the paper will present the sub-competences adjusted with the needs for Indonesian novice translators. Some might be taken from the existing ones, several could be developed from them, and some may be combined. These subcompetences will be provided with detailed explanation and some examples on how to achieve them. The first and second subcompetences involve language or linguistic competence, but the present paper will divide this competence into the source language competence and the target language competence. The source language competence is basically the ability to comprehend the source text thoroughly and deeply so that the message can be transferred to the target text. Based on Shreve et al. (1993)'s research findings, reading for translation shows deep understanding just like reading for paraphrasing, deeper than reading for comprehension. Thus, for Indonesian novice translators, they have to improve their reading skills and vocabulary for both Indonesian and a foreign language they are studying and learn to do paraphrasing on their reading texts to increase their comprehension. Understanding the source text in-depth is necessary for the successful transfer of the message to the target text.

The second sub-competence is the target language competence which is the ability to produce target language expressions naturally, appropriately, and correctly. This ability involves grammar knowledge and writing skills, in both Indonesian as the mother tongue of the Indonesian novice translators and a foreign language they are learning. Besides grammar and writing skills, the knowledge on spelling and punctuation is also crucial to be applied when producing the target text. Although the source text comprehension might be impeccable, without good grammar and writing skills of the target language the translation will not be successful. The third sub-competence is interlinguistic competence, which is the awareness of lexical, syntactic, and stylistic differences between the source language (SL) and the target language 
(TL). For example, in Japanese the verb is usually located at the end of a sentence, while in English the verb is put after the subject most of the time, almost similar with Indonesian language. Hence, when translating a Japanese sentence into Indonesian, a translator must be aware of putting the verb in the right place. With the awareness of these interlinguistic differences, novice translators will be more careful in translating from the SL to the TL. The fourth sub-competence is the cultural competence, which is the acquisition of cultural, historical, political, sociolinguistics knowledge of both source and target languages, so a translator will appropriately and successfully translate a text or transfer the message from the SL to the TL. For instance, when the pronoun 'you' in English is translated into Indonesian, we must be aware of whom 'you' refers to, as in Indonesian language there are many personal pronouns meaning 'you' depending on the age, social distance, position, etc. Thus, the pronoun 'you' can be Anda, kamu, kalian, Bapak, Ibu, elu, ente, etc. If we do not pay attention to the culture of either SL or TL, we might be considered impolite. If 'you' is translated into ' $k a m u$ ', while the person referred to is an older man, then the target text will sound rude. The proper translation should be 'Bapak', for instance. If 'you' refers to an old woman, then it should be translated into ' $I b u$ ', and so on.

The fifth sub-competence is transfer competence, which is the ability to transfer the message from the SL to the TL successfully and appropriately, by applying the proper translation ideology, strategies, methods, and procedures with the text type, following the instructions or translation brief, and paying attention to the purpose and targeted audience (skopos). All those will guarantee the successful translation results. For example, a translator has to follow the translation brief in order to do the translation job successfully. In the translation brief, it might ask the translator to translate an academic text into a story for children, which means there should be a shift in the language from formal and 'adult' language into the language used by children, and many other shifts. The sixth subcompetence is textual competence, which is the ability to be aware of text genre conventions in the SL and TL. The genre conventions from one language to another are different. For instance, Indonesian newspapers are written in a circular way where some information is usually repeated several times, while English newspapers are written straight to the point and information is not repeated. Moreover, this sub-competence is also concerned with the different conventions from one text type to another. A legal text will have different characteristics, a different format, and different language register from a journalistic text, for example. The seventh sub-competence is subjectknowledge competence or thematic competence, which is the awareness of learning further some subjects related to the text being translated. For example, when translating a text on forestry, then one should learn about forestry more. How is this done? One can take university courses on forestry, read field-specific journals on forestry, search any information related to forestry to retrieve and store glossaries on this subject.

The eight sub-competence is technological competence, which is the ability to work with CAT (Computer Assisted Translation) tools, word processing features, documents in various formats, etc. Translation technology consists of fully automated translation known as machine translation (MT) and CAT tools. MT does the translation by itself without the help of human translators. Everyone can just type a word or an expression on the MT to have the automated translation results. However, MT is still considered problematic as the results are often not successful or known as 'garbage in, garbage out', which means the result from MT is not the successful ones as they still need to be edited very much by human translators. The examples of MT are Systran 1940, Babel Fish (since 1997), Google translate, etc. CAT tools, in contrast, are the machines that help human translators to work faster and more efficiently. These machines still require human translators to work on the translation projects, so the machines do not automatically produce translation results. The tools consist of Translation Memory (TM), which restores words, phrases, clauses, or expressions from the previous translation work a translator has done and retrieves in a new translation work if there are some similar or quite similar words, 
phrases, clauses, or expressions, and Terminology Management system, which manages and stores terms acquired from the previous translation work. There are several brands of CAT tools, such as SDL Trados, MemoQ, Wordfast, OmegaT, etc. The brands of CAT tools can be seen in Figure 1 below. Moreover, the inside of CAT tools, which is the alignment, can be seen in Figure 2 below. The alignment is where the interface shows the source text and the target text appearing next to each other. With the advanced technology, the development of translation technology is quite fast, and in developed countries like the US, several European countries, and others the translators have to use CAT tools. In Indonesia, some professional translators have already used them too to assist with their work, although this phenomenon is not yet the mainstream in this country.

The ninth sub-competence is terminological competence, which is the ability to manage terms acquired manually or with the aids of CAT tools. This competence involves familiarity with key terminology and the ability to find, store, and manage terms quickly. Human translators are not the living dictionaries', so it is more important for them to be able to manage and retrieve terms than to memorize or internalize them. The more professional the translators, the higher the degree of terminological complexity that they acquire. The example of managing terms using CAT tools (or using Terminology Management system) can be seen in Figure 3 below. The tenth sub-competence is research competence, which is the ability in information retrieval strategies, such as finding terms, reading assistive texts, doing translation brief-oriented research like searching for the purpose and the audience of the target text. It will not suffice to search for terms or expressions in a dictionary or several dictionaries, either bilingual or monolingual. A professional translator should dig further by reading assistive texts. Assistive texts consist of parallel texts and background texts. The parallel texts are the texts with the same topic, purpose, target audience, and genre as the texts to be translated, while the background texts have the same topic, but have a different purpose, target audience, or genre. By reading the assistive texts, a translator will obtain terms and expressions suitable with the subject matter of the text translated. The eleventh sub-competence is professional competence or sometimes known as ethical competence, which is the awareness of understanding the work ethics and responsibility of translation jobs. For example, a translator must keep the source text and the target text confidential when the client asks them to. A translator must be honest when offering their service to a client. If they can only work on literary text translation, then they should not take a legal text translation job, because if they take it and they do a bad job on it, it will be detrimental for the client and the translator will lose the trust from the client. Finishing the translation project according to the deadline is also one of the work ethics.

\section{Figure 1. Brands of CAT tools}

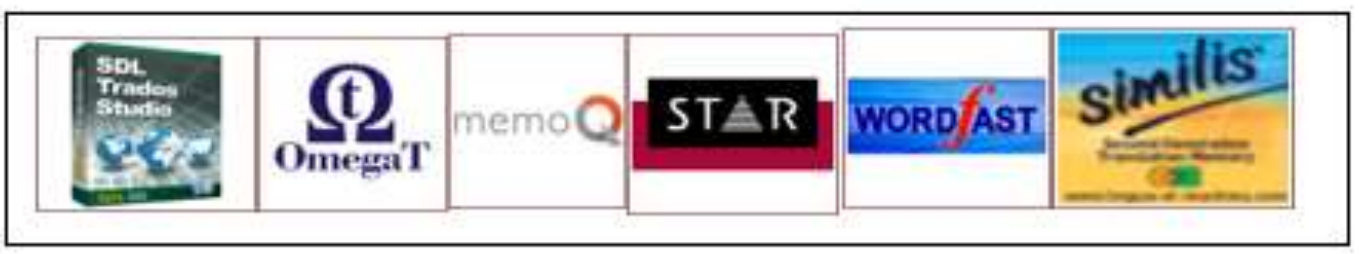


Figure 2. The alignment inside of the CAT tools

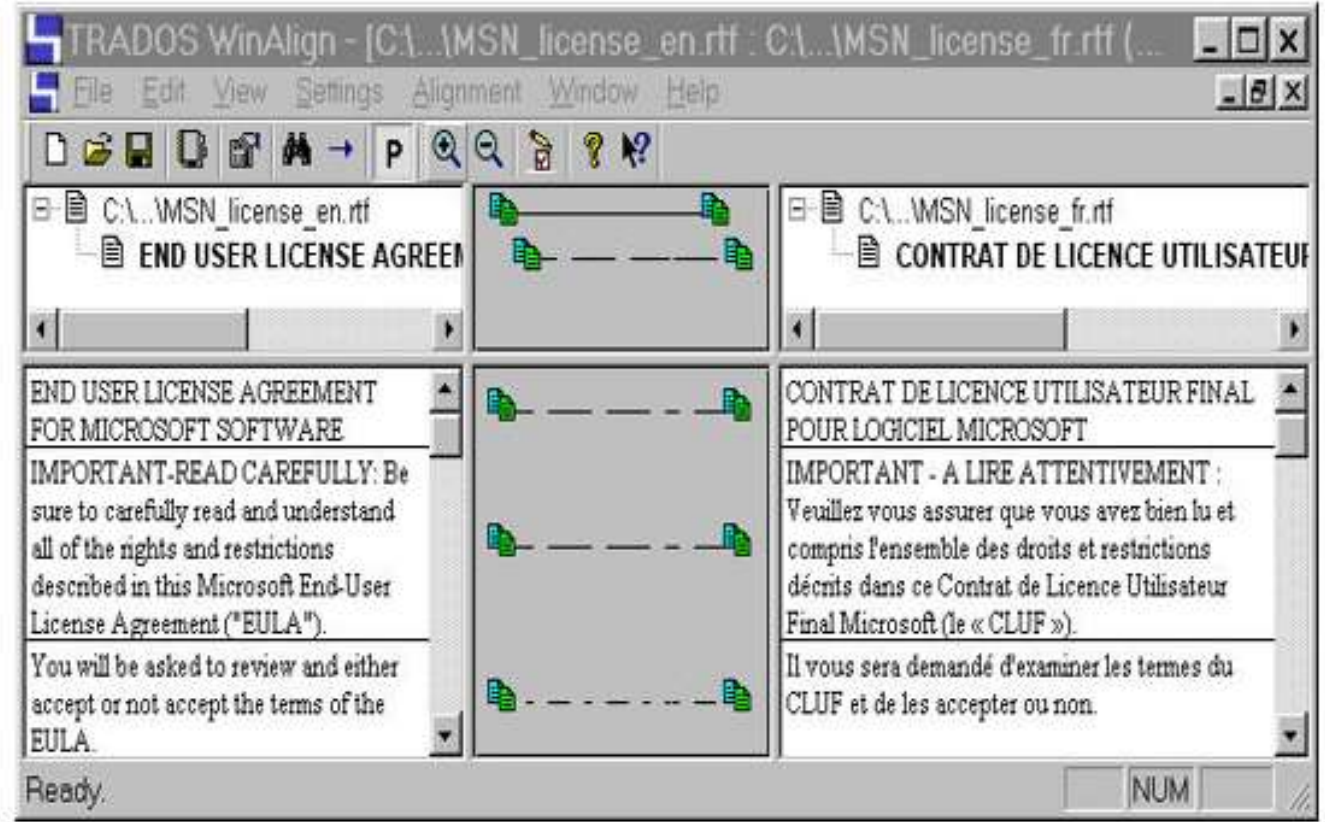

Figure 3. SDL Terminology Management

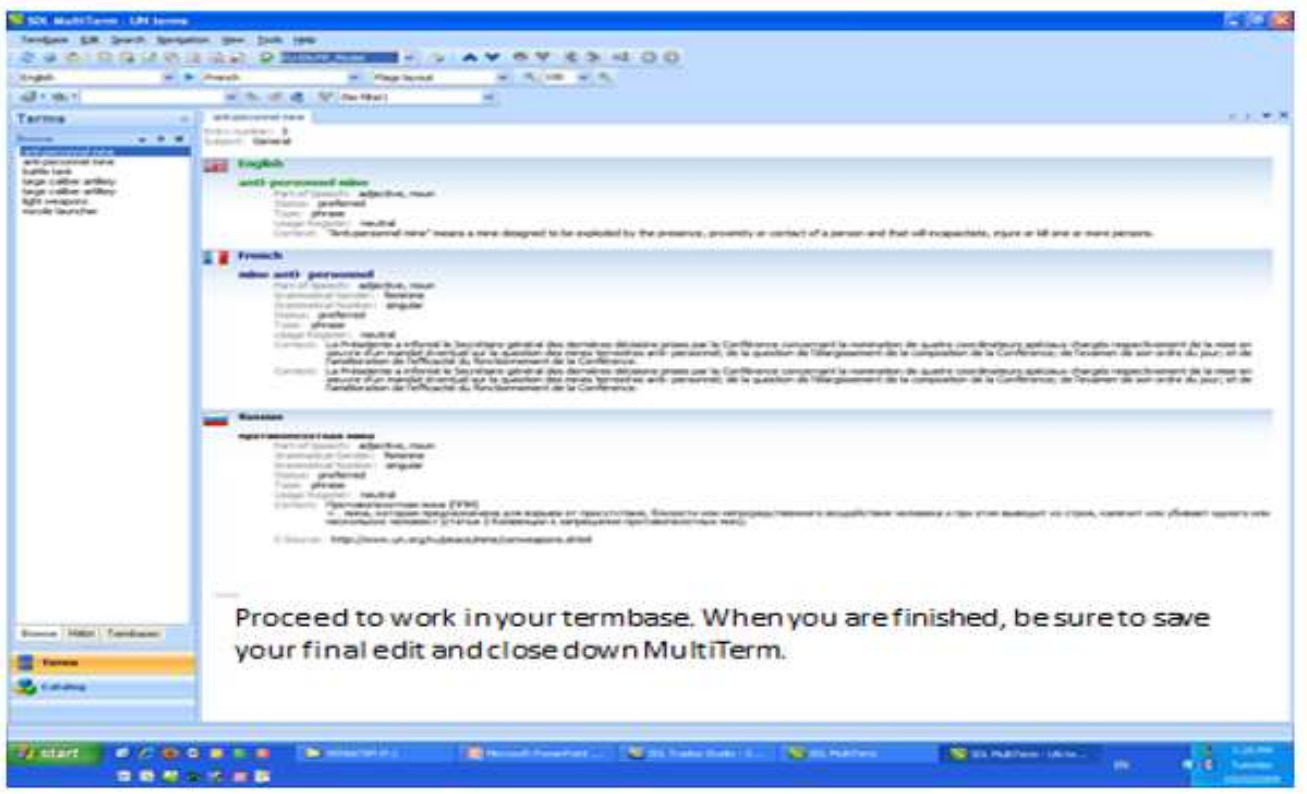

The twelfth sub-competence is service provision competence which is the knowledge of the business of translation. This competence requires translation business skills, translation business system skills, communication skills, and interpersonal skills (NAATI, 2015, p.7). This competence also makes the translators understand how to manage a translation agency or how to become a successful free-lancer. The thirteenth subcompetence is theoretical competence, which is the ability to make decisions while doing translation and justify one's translation in general based on theoretical models. This competence is similar with the strategy competence, as it helps translators to solve 
problems in doing translation. Moreover, it involves understanding and applying translation ideology, translation strategies, translation methods, translation procedures, etc. If a translator has learned about the ideology, strategies, methods, and procedures, he or she will gain insight on how to transfer the message successfully and properly from the ST to the TT.

Some theories may be formulated from practice, whereas some other theories might not. However, all those theories will help make the novice translators become more careful and wiser in doing translation. For example, when translating the expression 'their relationship has evaporated', a novice translator might translate that into 'hubungan mereka telah menguap'. It is true that the verb 'to evaporate' means 'menguap'; nevertheless, the TT sounds not natural in Indonesian. To solve this problem, that novice translator should learn about one of the procedures called modulation, which allows the changing of the meaning of words or expressions with a different point of view or scope to achieve successful, acceptable, and natural translation. Thus, instead of 'menguap' the word 'membeku (to freeze) sounds better in the result, so the TT becomes 'hubungan mereka telah membeku.' Hence, theory cannot be considered useless for practice. In contrast, it can assist novice translators to improve their translation results.

Several TS scholars have mentioned psycho-physiological competence and interpersonal or social competence. However, the present paper believes that those two competences are quite abstract and have the concrete form in professional or ethical competence. Thus, it is not necessary to have the psycho-physiological competence and interpersonal or social competence described as part of translation competences here as they are overlapped with other competences. So far, these thirteen competences are sufficient for novice translators to learn and accomplish if they wish to be professional translators in the future. Like any profession, being a professional translator will acquire hard work and time to practice.

\section{Conclusion}

For a novice translator to become a professional translator, it is not adequate to just become a bilingual or to have only language or linguistic competences, both source text competence and target text competence. It requires many more other competences which a novice translator must learn, achieve, and improve. Those thirteen competences (source text competence, target text competence, interlinguistic competence, cultural competence, transfer competence, textual competence, subject-knowledge competence, technological competence, terminological competence, research competence, professional competence, service provision competence, and theoretical competence) are the results of the literature study method and may still need to be added or reduced as time goes by. In the past, terminological and technological competences might not have been considered important to be acquired in the translation world as the technology was non-existent back then. Now, they are essential with the progress of advanced technology. Hence, in the future, it is possible that there will be other competences emerging considered as crucial to do translation jobs.

This present study is a review paper on translation competences, as it explores many journal papers on this topic. This kind of study is new and might be the only one in Indonesia, and it is important for Indonesian novice translators to know and understand those competences. For future research, an empirical study is necessary to discover whether Indonesian professional translators have already achieved all the competences discussed or to compare the competences of the 5-year experienced translators with the competences of the 10-year experienced translators, for instance. Hopefully, this paper and its future research will enhance the translation world in Indonesia. 


\section{References}

Beeby, A. et al. (2000). An empirical model for investigating translation competence, a paper presented at the conference Research Models in Translation Studies, UMIST, Manchester, UK.

Cheng, S. (2017). Translation competence development among learners: A problemsolving perspective. An unpublished dissertation at the University of Manchester.

Delisle, J. (1992). Les manuels de traduction: Essai de classification. TTR V(1), pp.1747.

Eser, O. (2015). A model of translator's competence from an educational perspective. In International Journal of Comparative Literature \& Translation Studies Vol. 3 No. 1 January 2015, pp.4 15.

Fox, O. (2000). The use of translation diaries in a process-oriented translation teaching methodology. In: Schäffner, C. \& Adab, B. (eds.) Developing Translation Competence. Amsterdam/ Philadelphia: John Benjamins Publishing Company, pp.115-130.

Harris, B. (1977). The importance of natural translation. Working papers on bilingualism, 12 pp. 96-144.

Harris, B. \& Sherwood, B. (1978). Translating as an innate skill. In D. Gerver \& W. Sinaiko (Eds.), Language interpretation and communication. New York: Plenum Press, pp. 155-170.

Hurtado Albir, A. (2007). Competence-based curriculum design for training translators. The Interpreter and Translator Trainer. 1(2), pp.163-195.
(2015). The acquisition of translation competence: Competences, tasks, and assessment in translator training. In Meta vol. 60 (2) August 2015, pp. 255 280.

Kelly, D. (2007). Translator competence contextualized. Translator training in the framework of higher education reform: In search of alignment in curricular design. In: Kenny, D. \& Ryou, K. (eds.) Across Boundaries: International Perspectives on Translation Studies. Cambridge: Cambridge Scholars Publishing, pp. 128142.

Lörscher, W. (1986). Linguistic aspects of translation processes. In House, J. and Blum-Kulka, S. (eds.), Interlingual and intercultural communication. Tübingen: Narrr, pp. 277-292.

Mulder, M., Gulikers, J., Biemans, H., \& Wesselink, R. (2009). The new competence concept in higher education: Error or enrichment? Journal of European Industrial Training, 33(8/9), pp.755-770.

NAATI. (2015). NAATI translator certification: Knowledge, skills and attributes. Available:https://www.naati.com.au/m edia/1059/translator_ksa_paper.pdf [Accessed 7 Oct 2018].

PACTE Group. (2000). Acquiring translation competence: Hypotheses and methodological problems in a research problem. In Beeby. A., Ensinger, D., Presas, M. (eds.) Investigating Translation. Amsterdam: John Benjamins, pp. 99-106.

(2003). Building a translation competence model. In Alves, E. (ed.) Triangulation Translation: Perspectives 
in Process Oriented Research. Amsterdam: John Benjamins, pp. 43-66. - (2005). Investigating translation competence: Conceptual and methodological issues. In Meta, 50 (2), pp. 609-619.

. (2011). Results of the validation of the PACTE translation competence model: Translation project and dynamic translation index. In O'Brien, S. (ed.) Cognitive explorations of translation. London and New York: Continuum International Publishing Group, pp. 3053.

Roberts, R.P. (1984). Traduction et Qualité de langue. Actes du colloque, Société des traducteurs du Québec/Conseil de la langue française. Québec: Editeur official du Québec, pp. 172-184.

Schäffner, C. (2000). Running before walking? Designing a translation programme at undergraduate level. In: Schäffner, C. \& Adab, B. (eds.) Developing Translation Competence. Amsterdam/ Philadelphia: John Benjamins Publishing Company, pp.143-156.

Shreve, G. M., Schäffner, C., Danks, J., \& Griffin, J. (1993). Is there a special kind of reading for translation? Target, 5, pp.2142.

Shreve, G. (1997). Cognition and the Evolution of Translator Competence. In Danks, J. \& Shreve, G. (eds.), Cognitive Processes in Translation and Interpreting. Thousand Oaks, Ca: Sage, pp.120-136.

Toury, G. (1986). Natural translation and the making of the native translator. TEXTconTEXT, 1, pp. 11-29.
Vienne, Jean. (1998). Teaching what they didn't learn as language students. In Malmkjaer, K. (ed.), Translation and Language Teaching. St. Jerome, pp. 111116.

Wills, W. (1976). "Perspectives and limitations of a didactic framework for the teaching of translation," in Brisline, R.W. (ed.), Translation. New York: Gardner Press, pp. 117-137. 